\title{
Sensitivity to Intravenous Anaesthetics: A Report of Three Cases
}

\author{
J. W. DUNDEE, \\ R. S. J. CLARKE, \\ E. S. K. ASSEM, \\ J. M. GASTON, \\ S. R. KEILTY, J. A. SUTTON, \\ D. GRAINGER
}

British Medical fournal, 1974, 1, 63-65

followed reports of sensitivity to Althesin in anaesthetic journals.

We report here the cases of three patients who showed

Summary

Three patients with sensitivity to an intravenous anaesthetic -thiopentone, propanidid, and Althesin (alphadolone and alphaxalone)-are described. In the cases of thiopentone and Althesin the reaction was characterized by cardiovascular collapse, while bronchospasm also occurred with thiopentone. The reaction to propanidid was a direct skin sensitivity. All patients had a personal or family history of asthma and all had been previously exposed to the offending drug. A leucocyte challenge test showed an allergic response to thiopentone and Althesin in two patients but gave a negative result in the patient with the skin reaction. Allergic reactions can occur to all types of intravenous anaesthetics in a few patients.

\section{Introduction}

With the addition of eugenols and steroids to the wellestablished barbiturates in the field of intravenous anaesthetics the problems of allergy and idiosyncrasy are of great importance. Though we do not know the factors involved there is evidence to suggest that reactions are more likely to occur in patients with a history of asthma, in those known to be sensitive to other drugs, and possibly in partients who have received the same agent or a similar one on a previous occasion. We do not know whether idiosyncrasy and allergy are more likely to occur with any one panticular intravenous anaesthetic. There have been few reports of sensitivity to the barbiturates, and as abnormal reactions to these drugs are fully documented in textbooks they are unlikely to be reported in journals; however, anaesthetists may be more inclined to report similar occurrences after the use of Althesin propanidid (alphadolone and alphaxalone) or because of their more recent introduction.

In a recent letter Dundee and Clarke (1973) expressed their wish to collect details of a large number of patients showing sensitivity to any intravenous anaesthetic with a view to determining the factors involved and the relative likelihood of reactions with the different agents available. The request

\footnotetext{
Department of Anaesthetics, Queen's University of Belfast, Belfast BT12 6BJ

J. W. DUNDEE, M.D., F.F.A., R.C.S., Professor of Anaesthetics

R. S. J. CLARKE, M.D., F.F.A., R.C.S., Reader in Anaesthetics

Department of Pharmacology, University College Hospital, London WC1E 6AU

E. S. K. ASSEM, PH.D., M.R.C.P., Senior Research Fellow

R.A.F. Halton, England

J. M. GASTON, M.B., F.F.A., R.C.S., Squadron Leader

Royal Belfast Hospital for Sick Children, Belfast BT12 6BE

S. R. KEILTY, M.B., F.F.A. R.C.S., Consultant Anaesthetist

Glaxo Laboratories, Greenford, Middlesex

J. A. SUTTON, M.B., B.S., Medical Adviser

Royal Victoria Hospital, Belfast BT12 6BA

D. GRAINGER, M.B., Registrar in Anaesthetics
}

sensitivity to a barbiturate, a eugenol, and a steroid anaesthetic and suggest that sensitivity is not confined to any one group. Leucocyte challenge (Assem and McAllen, 1970) and skin sensitivity tests were carried out in an attempt to determine whether the reaction was based on an immune mechanism of the immediate allergic type or on direct histamine release.

\section{Case I. Thiopentone Sensitivity}

The patient was a man aged 19 with a history of asthma and eczema but no recorded drug allergies. He had had three previous anaesthetics, one when he was 3 years old and one for tooth extraction in his early teens. Both of these were uneventful. The third, six weeks before the present incident, was for repair of a finger wound. On that occasion, after induction with $250 \mathrm{mg} 2.5 \%$ thiopentone and $75 \mathrm{mg}$ suxamethonium he collapsed with generalized bronchospasm, hypotention, and tachycardia; he recovered rapidly, however, after an intravenous infusion of $500 \mathrm{ml} 5 \%$ dextrose had been set up and $250 \mathrm{mg}$ aminophylline and $100 \mathrm{mg}$ cortisol had been given intravenously.

Without full knowledge of the previous episode the patient was premedicated with $75 \mathrm{mg}$ pethidine, $50 \mathrm{mg}$ promethazine, and $0.6 \mathrm{mg}$ atropine. Induction of anaesthesia was with $250 \mathrm{mg} 2.5 \%$ thiopentone followed by $50 \mathrm{mg}$ suxamethonium. He complained of some pain when the thiopentone was being given but there was no evidence of perivascular or intra-arterial injection. He coughed on losing consciousness and within 30 seconds had developed a central facial flush and was becoming cyanosed. He had marked bronchospasm and it was impossible to inflate the chest. Within a further 30 seconds he was grossly hypotensive and intensely cyanosed despite administration of oxygen. An intravenous infusion of $500 \mathrm{mg}$ compound sodium lactate was started and the patient was given $500 \mathrm{mg}$ aminophylline and $200 \mathrm{mg}$ cortisol. This produced a temporary improvement but he rapidly became cyanosed again. Spontaneous respiration returned within five minutes of induction but he remained cyanosed when breathing pure oxygen and had not regained consciousness. He was given $200 \mathrm{mEq}$ sodium bicarbonate and an arterial blood sample taken immediately afterwards showed an oxygen tension of $25 \mathrm{~mm} \mathrm{Hg}$ and a $\mathrm{PaCO}_{2}$ of $135 \mathrm{~mm} \mathrm{Hg}$. He was immediately given a further $800 \mathrm{mg}$ cortisol followed by $24 \mathrm{mg}$ dexamethasone in $8-\mathrm{mg}$ increments. This produced a marked improvement and the bronchospasm started to relax. Within one hour he had completely recovered, but the operation was abandoned.

Subsequently the patient showed no abnormality apart from some pharyngeal oedema and extensive venous thrombosis at the injection site.

Four months later skin and leucocyte challenge tests showed him to be allergic to both thiopentone and pentobarbitone but not, apparently, to methohexitone. His leucocytes released histamine on challenge with thiopentone, pentobarbitone, propanidid, and Cremophor (polyethoxylated castor oil), which is a vehicle for both Althesin and propanidid, but not with either alphadolone or alphaxalone. Moreover, alphadolone and alphaxalone seemed to stabilize the basophil leucocyte membrane, since in their presence histamine release was less than in control samples and they produced inhibition of histamine release by the various agents mentioned above. Though the patient's total serum IgE was near the lower limit of normal $(<10 \mathrm{mg} / \mathrm{ml})$ his leucocytes released a high proportion of their histamine content when challenged with anti-IgE ("reversed" leucocyte anaphylaxis), suggesting an abnormally high level of leucocyte-bound IgE (Assem et al., 1971), which was compatible with his various allergies. Skin tests gave strongly positive reactions to many allergens, including 
pollens, mites, house dust, horse dandruff, cat fur, etc., and also to thiopentone and pentobarbitone, but only slight reactions to Althesin and propanidid. A very weak response was obtained with alphadolone but the test with alphaxalone gave a completely negative result.

\section{Case 2. Propanidid Sensitivity}

A 42-year-old male consultant anaesthetist, allergic to crab meat and cray fish, had a family history of asthma but was not himself an asthmatic. He had worked in the field of anaesthesia for 18 years and had experience with all types of drugs including, during investigations, many new intravenous anaesthetics. Before the present incident he has used propanidid for about two years. He took part in the first British clinical trials of this drug and of its predecessor G 29505. Four previous anaesthetics involving the use of barbiturates had evoked no abnormal response.

He woke one morning with eyes badly swollen and lids very sore and itchy. His arms became very itchy and he developed general malaise to the extent that he could not work in the operating theatre and had to go home to bed. He was given chlorpheniramine maleate (Piriton), which made him drowsy and irritable. This episode lasted two days but identical symptoms with much contamination of his skin recurred one week later after the use of large quantities of propanidid. The facial swelling became marked and on this occasion took about three days to subside.

He gave no anaesthetics for a month and immediately on his return used methohexitone, nitrous oxide, and oxygen with no adverse result. Next day he used propanidid in large doses with some contamination of his hands and the same sequence of events occurred; this time it was much more severe and his lips and face were noticeably swollen (see fig.). It was seven days before symptoms subsided and even on the tenth day one hand was very itchy and the skin was beginning to desquamate. He gave no further anaesthetics for 10 days but on return to work in the operating theatre used methohexitone, nitrous oxide, and oxygen without trouble.

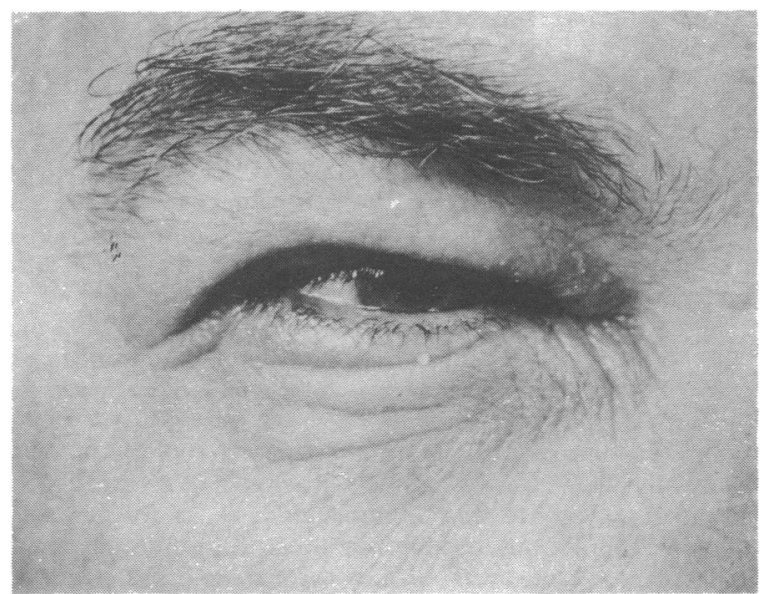

Case 2. Facial swelling after contamination with propanidid.

The use of propanidid was avoided completely, but four months later he was working in a room where there were some swabs contaminated with propanidid. An episode similar in severity to the previous one occurred even though there was no obvious direct contact with the anaesthetic. When he recovered patch skin tests were carried out with propanidid and Cremophor. These showed a marked reaction to the propanidid but not to the solvent. On another occasion, about a year later, he passed a tracheal tube on a patient who had been induced with propanidid. There had been difficulty in intubation, the level of anaesthesia had been reduced and the patient coughed violently on to the anaesthetist's face. This was followed by further facial swelling.

There was no further exposure to propanidid until skin tests were carried out nine years later. Intradermal injections of $0.03 \mathrm{ml}$ propanidid and Althesin, both in their concentrated form and in 1/10 and 1/100 dilutions, were given with two dilutions of the vehicle of Althesin (Cremophor). There was no reaction to either the Althesin or the solvent but a marked response to all concentrations of propanidid occurred. The reaction was not of the immediate type. Within 30 minutes the injection sites started to itch. Indurated weals surrounded by erythema appeared after one hour, the induration reaching maximum size ( $50 \mathrm{~mm}$ in diameter) after eight hours and persisting at the site of maximum drug concentration for over $\mathbf{4 8}$ hours (mean diameter $25 \mathrm{~mm}$ ). The patient also gave a positive response to a propanidid patch test.

Leucocyte challenge tests with the same test substances as well as anti-IgE, which are all strict correlates of immediate-type allergy, gave negative results. Total serum IgE was also normal.

\section{Case 3 Althesin Sensitivity}

An 8-year-old boy was admitted to hospital for a skin graft to his thigh. There was a family history of asthma though he was not an asthmatic and he had shown a severe skin reaction to iodine. He had had three previous anaesthetics for his condition; one was induced with thiopentone, one with Althesin, and the third was with nitrous oxide, oxygen, and methoxyflurane. The present event occurred exactly four weeks after the previous administration of Althesin and three weeks after the inhalational anaesthetic. Premedication was with $4 \mathrm{mg}$ morphine and $0.6 \mathrm{mg}$ atropine and induction was with Althesin. He was given $1 \mathrm{ml}$ and 30 seconds later he coughed. There was widespread vasodilatation with flushing and the systolic blood pressure fell to $40 \mathrm{~mm} \mathrm{Hg}$. Within a further 30 seconds he became cyanosed and tachycardia was marked. He was treated with intravenous fluids and $100 \mathrm{mg}$ cortisol and recovered consciousness in 10 minutes. The unconsciousness was unexpectedly prolonged after this small dose of Althesin to a patient weighing $23 \mathrm{~kg}$.

In-vitro tests for immediate-type allergy to Althesin (leucocyte histamine release) gave positive results with the whole Althesin with vehicle and with both alphadolone and alphaxalone but the serum IgE was normal.

\section{Discussion}

These patients each showed different abnormal reactions to intravenous anaesthetics. With thiopentone and Althesin the response was characterized by arterial hypotension and noticeable flushing of the skin; in addition bronchospasm occurred after thiopentone. All were presumably due to release of pharmacologically aotive substances, including histamine, which may have been the result of idiosyncrasy or allergy. In contrast the reaction to propanidid appeared to be a direct skin sensitivity to the drug but not to the solvent, the clinical manifestations and tests suggesting contact dermatitis.

Until a few years ago allergy to thiopentone was not thought to exist, and several textbooks dogmatically commented on this. In recent years, however, there have been reports suggesting that an allergic type of reaction to this drug does occur, though it must be extremely rare. Clark and Cockburn, who described a case in 1971 , also reviewed reported cases at that time. Later Dundee and Wyant (1973) reviewed the literature and recorded 13 apparently definite cases of anaphylactoid response to thiopentone (including the case reported here). There are also four or five other reports of patients in whom only the skin sensitivity occurred.

Though the patient described here showed only skin sensitivity to propanidid reactions similar to those described for thiopentone and Althesin have been recorded after its use. Some of these may have been the result of inadvertent overdosage of a very short acting drug but there are undoubtedly cases reported of true sensitivity to this eugenol. Clarke (1973) reviewed these cases and found 23 incidents of acute adverse reactions to propanidid. Eleven of these patients had had the drug on a previous occasion; thus acquired allergy was the likely mechanism in them, while in the remainder the reaction might be described as idiosyncratic in the absence of any known previous exposure to eugenols. Though hypotension and flushing were the main symptoms seven patients had some bronchospasm.

In recent months there have been a number of reports of sensitivity reactions to Althesin similar to that described here. 
(From sales figures the incidence of these appears to be lower than 1 in 25,000 .) In some of these patients a history of prior exposure without undue reaction was reported, thus favouring the diagnosis of classic immediate-type allergy-that is, a reaction presumably mediated by reaginic antibodies (mainly IgE). Raised plasma levels of this class of antibody confirm an immediate-type allergy but a normal level does not exclude it. In other patients a similar history was not obtained and thus the reactions appeared to be due to idiosyncrasy, which is defined as a qualitatively abnormal reaction response to the drug - that is, it is not part of its normal pharmacological action and it is not immunologically mediated (Assem, 1967). When reviewing these reports it becomes clear that asthma is a frequent feature in these patients. In some instances premedication (Avery and Evans, 1973) or the use of other drugs may have been involved and recent reports suggest that similar reactions may occur to muscle relaxants (Jerums et al., 1967; Hainsworth and Bingham, 1970).

This report aims to stimulate interest in adverse reactions to intravenous anaesthetics so that the incidence of such reactions to all drugs can be estimated and compared. It is hoped that this publication will encourage reporting of cases both to the Committee on Safety of Medicines and also in response to the request of Dundee and Clarke (1973).

\section{References}

Assem, E. S. K. (1967). Hospital Medicine, 2, 199.

Assem, E. S. K., and McAllen, M. K. (1970). British Medical fournal, 2, 504 Assem, E. S. K., Turner-Warwick, M., Cole, P., and Shaw, K. M. (1971) Clinical Allergy, 1, 353.

Avery, A. F., and Evans, A. (1973). British fournal of Anaesthesia, 45, 301. Clark, M. M., and Cockburn, H. A. (1971). British fournal of Anaesthesia, 43, 185 .

Clarke, R. S. J. (1973). In Intravenous Anaesthesia, ed. J. W. Dundee and G. M. Wyant. Edinburgh, Churchill Livingstone.

Dundee, J. W., and Clarke, R. S. J. (1973). Lancet, 1, 831.

Dundee, J. W., and Wyant, G. M. (1973). In Intravenous Anaesthesia, ed J. W. Dundee and G. M. Wyant. Edinburgh, Churchill Livingstone. Hainsworth, A. M., and Bingham, W. (1970). Anaesthesia, 25, 105.

Jerums, G., Whittingham, S., and Wilson, P. (1967). British fournal of Anaesthesia, 39, 73 .

\title{
Primary Neuropathic Amyloidosis in Three Brothers
}

\author{
A. ZALIN, A. DARBY, S. VAUGHAN, E. B. RAFTERY
}

British Medical fournal, 1974, 1, 65-66

\section{Summary}

Neuropathic primary amyloidosis has not been previously described in an English family. We present the clinical and pathological findings in three brothers with this condition and suggest that they have suffered from that form of the disease described originally by Andrade.

\section{Introduction}

Four clinical patterns of familial neuropathic amyloidosis have been delineated. The first, described by Andrade (1952), originated in Pontugal, and families with this form of the disease but without evidence of Portuguese ancestry have been found in the United States (Shulman and Bartter, 1956), Germany (Delank et al., 1965), and Japan (Araki et al., 1968). The onset is usually in the third or fourth decade with neuropathy starting in the feet. Autonomic disturbance is common and diarrhoea often develops. The course is rapid, with death from cachexia and infection within 4 to 12 years.

The second clinical type was reported by Rukavina et al. (1956) in a family of Swiss origin in Indiana, U.S.A., and was extended to include a large kindred in Maryland (Mahloudji et al., 1969). In this form the onset is in the hands, and manifestations outside the nervous system are rare. The prognosis is relatively poor, patients often dying of unrelated causes. Van Allen et al. (1969) described another pattern in a kindred of English-Soottish-Irish descent in Iowa. Here the onset is in

\footnotetext{
Northwick Park Hospital and Clinical Research Centre, Harrow HA1 3UJ

A. ZALIN, M.B., M.R.C.P., Senior House Physician (Present appointment: Lecturer in Experimental Pathology, Birmingham University)

A. DARBY, M.B., M.R.C.PATH., Senior Registrar, Department of Histopathology

S. VAUGHAN, M.A., B.CHIR., Senior House Officer

E. B. RAFTERY, M.D., M.R.C.P., Consultant Physician
}

the feet, renal involvement with death in uraemia is characteristic, and there is a high incidence of peptic ulceration. Diarrhoea and steatorrhoea are, however, absent. The fourth type was reported by Meretoja (1969) from Finland. The main features are a lattice dystrophy of the cornea and cranial neuropathy. The course is slow and any involvement of peripheral nerves is late and mild.

\section{Case Reports}

CASE 1

A 69-year-old man was admitted to hospital in June 1971 with a history of two years' progressive exertional dyspnoea and recent paroxysmal nocturnal dyspnoea. For 12 months he had suffered gradually-worsening numbness, tingling, and loss of temperature sensation below the knees in both legs. He had also noticed that he was stubbing his toes when going upstairs or when walking on uneven pavements. There had been some mild tingling of the tips of his fingers. The possibility of an autonomic neuropathy was suggested by his complaints of impotence, faintness on rising from a lying position, and alternating constipation and diarrhoea, the latter often being nocturnal.

Both his younger brothers had died (one at another hospital in the region and one in New Zealand) with paralysis and severe wasting. His three sisters were all well; his father died at 84 of heart failure and his mother at 78 with a cerebral infarct.

On examination he had bilateral basal crepitations but no other signs of heart failure. His blood pressure was $130 / 70 \mathrm{~mm} \mathrm{Hg}$ lying, falling to $100 / 60 \mathrm{~mm} \mathrm{Hg}$ standing. He had slight weakness of the intrinsic muscles of the hands, especially the abductor pollicis brevis and interossei. There was also weakness of dorsiflexion of the toes and ankles. The only sensory loss detected in the upper limbs was that of vibration sense up to the metacarpophalangeal joints. In the legs there was pronounced symmetrical sensory loss up to the knees. The perception of deep and superficial pain, temperature, and light touch were all impaired in this area. Vibration and position sense were normal but Romberg's sign was positive. The ankle jerks were absent and there was bilateral thickening of the ulnar and lateral popliteal nerves.

Investigations confirmed disease of the heart and of peripheral and autonomic nerves and showed impairment of renal function. On chest $x$-ray the heart was enlarged and the E.C.G. showed right bundle- 